\title{
The possibility of using new varieties of essential oil plants in medicinal plant production
}

\author{
Oksana Shevchuk ${ }^{1}$, Dmitry Konovalov ${ }^{2, *}$, Nadezhda Bakova $^{1}$, Anna Suslova ${ }^{1}$, and \\ Valeriya Orobinskaya ${ }^{3}$ \\ ${ }^{1}$ Federal State Budgetary Institution of Science "Nikitsky Botanical Garden of Order of the Red \\ Banner of Labor - National Scientific Center of the Russian Academy of Sciences, 298648 Nikita, \\ Yalta, the Republic of Crimea, Russian Federation \\ ${ }^{2}$ Pyatigorsk Medical and Pharmaceutical Institute - branch of the Federal State Budgetary \\ Educational Institution of Higher Education "Volgograd State Medical University" of the Ministry \\ of Health of the Russian Federation», Kalinina Ave., 11, 357532 Pyatigorsk, Stavropol Krai, \\ Russian Federation \\ ${ }^{3}$ North Caucasus Federal University in the city of Pyatigorsk, 40 let Oktyabrya Str., 56, 357500 \\ Pyatigorsk, Stavropol Krai, Russian Federation
}

\begin{abstract}
The collection of plants grown in the Nikitsky Botanical Garden is an inexhaustible source of plant resources. One such resource species is Thymus vulgaris L. Being a perennial, the species is traditionally used as an aromatic, essential oil and medicinal plant. Thyme herb is described as a medicinal raw material in many pharmacopoeias. Essential oil and phenolic compounds, which are considered the main active ingredients of this raw material, are a source of antiviral, antimicrobial, antioxidant, anti-inflammatory and other therapeutically significant activities of drugs created on its basis. The purpose of the presented research was to study the essential oil and develop some indicators of the quality of raw materials (herbs) of the new essential oil variety Thymus vulgaris cv. 'Fantasiya' cultivated in the Nikitsky Botanical Garden. As a result of the study, it was found that this variety of thyme allows to get 40 $\mathrm{kg}$ of essential oil per hectare, with a high content of the main components - thymol and carvacrol. Some indicators of the raw materials quality, as well as the qualitative composition of the essential oil and the quantitative content of the components identified in it, were determined.
\end{abstract}

\section{Introduction}

The plant collection of the Nikitsky Botanical Garden (NBG) contains more than 240 plant species that characterize the vegetation of different regions of the world. Representatives of more than 100 genera from several dozen families have been introduced here [1]. One of the main methods of introduction is the method of generic complexes, when species belonging to the same genus are involved in the study. A promising source of

\footnotetext{
${ }^{*}$ Corresponding author: d.a.konovalov@pmedpharm.ru
} 
medicinal plant raw materials containing thymol are species of the genus Thymus L., which is native to the Mediterranean. The collection of plant material for the creation of a collection of species of this genus was carried out by expedition trips to the Crimea, Transcaucasia, as well as by seeds extracting for delectus from various botanical gardens of the world [2].

The gene pool collection of the genus Thymus L. in the NBG includes 32 samples of the following species: Th. comosus, Th. kotschyanus, Th. mastichina, Th. nitens, Th. pulegioides, Th. richardii, Th. roegneri, Th. serpyllum, Th. striatus, Th. vulgaris, which differ significantly in the complex of economically useful traits and are adapted to different habitat conditions.

At present time, the world is constantly searching for new natural medicines that meet modern safety requirements. Plant-based drugs are characterized by low toxicity, a wide range of pharmacotherapeutic activities, a minimal risk of multiple drug resistance, and the possibility of long-term use without the development of an addictive effect [3]. Due to the decrease in the stocks of wild medicinal plant raw materials, the introduction of highly productive new varieties of medicinal plants into industrial culture is an urgent issue $[4,5]$.

Common thyme (Thymus vulgaris L.) is a perennial herbaceous plant (semi-shrub) belonging to the mint family (Lamiaceae). Traditionally used as a aromatic, essential oil and medicinal plant. In pharmacy, its herb, essential oil, as well as syrups, lollipops and tablets prepared on its basis are used [6]. The main biologically active compounds that determine the therapeutic effectiveness of thyme are essential oil and flavonoids.

Many pharmacological experiments in vitro and in vivo conducted over the past decade have shown the antibacterial, antiviral and antifungal activity of both thyme essential oil and its extracts [7-9].

Common thyme herb for medicinal use is harvested in the flowering phase. Pretreatment of raw materials includes drying, removal of coarse lignified stems and other organic and mineral impurities. Essential oil is obtained mainly from freshly harvested raw materials. It has long been recognized that the essential oil of this species exhibits antimicrobial properties against Staphylococcus aureus. It has a higher antibacterial activity than ampicillin against $S$. pyogenes and $S$. aureus, and also effectively inhibits the growth of Candida spp. [10].

Essential oil is used to make various preparations for rinsing the mouth, tooth powders and pastes, cough medicines. Preparations based on thyme herb (water infusion, liquid extract) are widely used in broncho-pulmonary pathologies to remove sputum, of a pronounced antibacterial and anti-inflammatory effect; it is a rich source of antioxidant compounds of phenolic nature, which contribute to the prevention of a number of diseases [11].

Thyme extract is active against herpes simplex virus of type 1 (HSV-1) and type 2 (HSV-2) [12].

The aim of the research was to study the essential oil and develop some indicators of the quality of raw materials (herbs) of the new essential oil variety Thymus vulgaris cv. 'Fantasiya' with the aim of expanding the raw material sources for the production of "Thymi vulgaris herba".

\section{Materials and methods}

The object of the study is the NBG selection variety Thymus vulgaris cv. 'Fantasiya'. The quantitative and qualitative characteristics of fresh and dried raw materials collected during the mass flowering phase in 2019-2020 were determined in accordance with the requirements of the general Pharmacopoeia article (OFS) of the State Pharmacopoeia of the Russian Federation (SF RF) of the XIV edition [13]: 
OFS 1.2.2.2.0013.15 - Total ash;

OFS 1.5.3.0006.15 - Determination of the content of extractive substances in medicinal plant raw materials and medicinal plant preparations;

OFS 1.5.3.0007.15 - Determination of moisture content of medicinal plant raw materials and medicinal plant preparations;

OFS 1.5.3.0010.15 - Determination of the essential oil content in medicinal plant raw materials and medicinal plant preparations;

FS.2.5.0097.18 - Thyme herb;

The determination of essential oil in fresh and dried thyme herb was carried out using the Ginsberg device (method 1), in accordance with the requirements of the SF XIII edition [14] in 2019-2020.

The analysis of the qualitative composition and the quantitative content of the individual components of the essential oil was carried out by gas-liquid chromatography with mass spectrometric detection (Kristall 5000.2, Chromatek, Russia), using the library data of mass spectra (NIST14 MS Search). The quantitative characteristics of the essential oil components were calculated by the normalization method recommended by the SF. Statistical processing of the analysis results was carried out on the basis of the software application Statistica 6.0.

\section{Results and discussions}

As a result of the selection work in 2007, the team of authors of the NBG bred by the method of individual selection from the seed population of thyme vulgaris a highly productive essential oil variety Fantasiya, cultivated in the conditions of the Southern coast of the Crimea since 2014 to obtain essential oil (authors L.A. Khlypenko, V.I. Mashanov, N.S. Mashanova, T.I. Orel, V.D. Rabotyagov) [15].

This variety has the following morphological features: stems with of a tetrahedral shape characteristic of representatives of the Lamiaceae family, green, greenish-grayish color. The leaves are short-stemmed, oblong-ovate, grayish-green, up to $5 \mathrm{~mm}$ long; slightly pubescent, with a central vein on the underside. Flowers: small, single, or in verticillasters. The two-sided calyx is reddish-yellow, the corolla is two-sided bluish-purple. This variety has minor differences from the standard described in the pharmacopoeia article on the morphological structure of leaves and stems. The variety is highly productive and is included in the State Register for the North Caucasus region. The content of essential oil in the herb is $0.64 \%$ in air-dry raw materials equivalent. With a yield of $65.4 \mathrm{c} / \mathrm{ha}$, the yield of essential oil is $41.9 \mathrm{~kg} / \mathrm{ha}$.

Taking into account that the raw material for the pharmaceutical industry can be either dried raw materials or essential oil, we analyzed the individual characteristics of the essential oil of the studied variety for compliance with the requirements of the SF RF XIV and some other pharmacopoeias (Table 1).

Table 1. Quantitative and qualitative characteristics of essential oil of Thymus vulgaris cv.

'Fantasiya' compared to the requirements of some Pharmacopoeias

\begin{tabular}{|l|c|c|c|c|}
\hline \multicolumn{1}{|c|}{ Criteria } & $\begin{array}{c}\text { T. vulgaris cv. } \\
\text { 'Fantasiya' }\end{array}$ & \multicolumn{3}{|c|}{ Pharmacopoeia requirements } \\
\cline { 4 - 5 } & $\begin{array}{c}\text { SF RF XIV } \\
\text { FS.2.5.0097.18 }\end{array}$ & European Thyme herb & $\begin{array}{c}\text { Republic of Belarus } \\
\text { Thyme herb }\end{array}$ \\
\hline $\begin{array}{l}\text { Essential oil content } \\
\text { in dry raw materials, } \\
\text { ml/kg, not less* }\end{array}$ & $13.6 \pm 0.77$ & 10.0 & 12.0 & 12.0 \\
\hline $\begin{array}{l}\text { Thymol, limits in } \\
\text { ranges, \%** }\end{array}$ & $40.8-55.7$ & \multirow{2}{*}{ Not regulated } & $37-55$ & $\begin{array}{c}\text { In total, not less } \\
\text { than } 40 \% \text { in es. oil }\end{array}$ \\
\cline { 1 - 1 } Carvacrol, limits in & $1.7-2.4$ & & $0.5-5.5$ & \\
\hline
\end{tabular}


ranges, \%*

* - average 2019-2020.

** - \% content in essential oil in dry raw materials equivalent.

According to the content and quality characteristics of the essential oil, the raw material of the studied variety exceeds the stated criteria in the European Pharmacopoeia and the Pharmacopoeia of the Republic of Belarus [16]. According to the data obtained, the content of essential oil in the raw material of $T$. vulgaris cv. 'Fantasiya' exceeds by $1.6 \%$ the indicators stated in these pharmacopoeias and is $13.6 \mathrm{ml} / \mathrm{kg}$ (Table 1).

The content of thymol and carvacrol in essential oil is an important criterion for its quality.

During the chromatographic study (HPLC-MS) of essential oils from fresh and dried thyme raw materials, 41 components were isolated, 39 components were identified. Essential oils differ slightly in their qualitative composition (Fig. 1, 2). The differences are mainly observed in the quantitative ratio of the main monoterpene components. The dominant component of oils is thymol.

Thymol content in various essential oil samples obtained from T. vulgaris cv. 'Fantasiya' raw materials during 2019-2020, ranged from $40.8 \%$ to $55.7 \%$ (in dry raw materials equivalent). The content of $p$-cymene - from $12.66 \%$ to $23.61 \%$; $\gamma$-terpinene -10.68 $8.27 \%$, and carvacrol - from $1.72 \%$ to $2.41 \%$ (in dry raw materials equivalent).

Thymol and its isomer carvacrol are natural monoterpene derivatives of $p$-cymene. Thymol, $\gamma$-terpinene, and $p$-cymene form an interconvertible biogenetic chain. A decrease in the content of one of the substances in this chain leads to an increase in the content of other substances in this series. The thymol content is $24 \%$ higher in oil obtained from fresh raw materials. The same pattern is observed for $\gamma$-terpinene: $10.68 \%$ in oil from fresh raw materials against $8.27 \%$ - from dry raw material. When drying the raw material, the content of $p$-cymene in the essential oil increases significantly, almost by 2 times: from $12.66 \%$ to $23.61 \%$. A comparison of the data obtained with the literature data $[8,9]$ shows that this variety belongs to the chemotype with a predominance of thymol and $p$-cymene in terms of the composition of volatile substances.

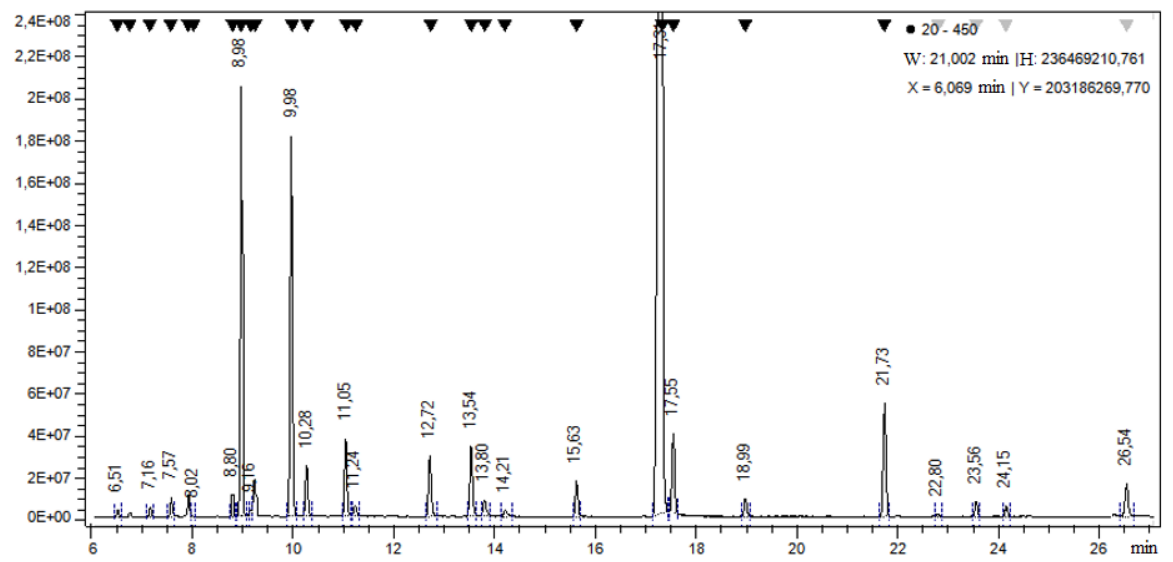

Fig. 1. Chromatogram of essential oil of Thymus vulgaris cv. 'Fantasiya', obtained from fresh raw materials 


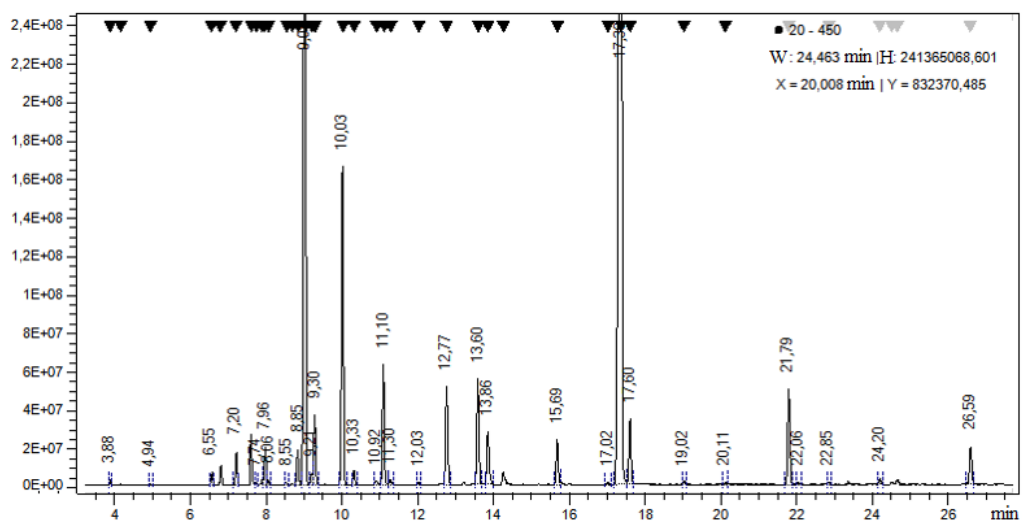

Fig. 2. Chromatogram of essential oil of Thymus vulgaris cv. 'Fantasiya', obtained from dry raw materials

Table 2. Study of some indicators of the quality of Thymus vulgaris cv. 'Fantasiya' raw materials

\begin{tabular}{|l|l|c|c|c|}
\hline \multirow{2}{*}{ No. } & Indicator & \multicolumn{2}{|c|}{ Fantasiya variety } & SF XIV requirements \\
\cline { 3 - 4 } & & $\mathrm{x}_{\mathrm{av} .} \pm \Delta \mathrm{x}$ & $\mathrm{E} \%$ & $\begin{array}{c}\text { FS.2.5.0097.18 / } \\
\text { FS.2.5.0047.15 }\end{array}$ \\
\hline 1 & Weight loss during drying & $9.30 \pm 0.04^{*}$ & 0.46 & No more than $13 \%$ \\
\hline 3 & Total ash & $8.00 \pm 0.04^{*}$ & 0.54 & No more than $12 \%$ \\
\hline 4 & $\begin{array}{l}\text { Extractive substances } \\
\text { extracted by water }\end{array}$ & $56.87 \pm 0.03^{*}$ & 0.05 & Minimum $18 \%$ \\
\hline 5 & $\begin{array}{l}\text { Extractive substances } \\
\text { extracted with ethyl alcohol } \\
30 \%,\end{array}$ & $41.02 \pm 0.04^{*}$ & 0.09 & Minimum $18 \%$ \\
\hline 6 & $\begin{array}{l}\text { Extractive substances } \\
\text { extracted with ethyl alcohol } \\
70 \%,\end{array}$ & $33.73 \pm 0.08$ & 0.25 & $\begin{array}{l}\text { Number of flavonoids in } \\
\text { terms of luteolin-7-O- } \\
\text { glucoside }\end{array}$ \\
\hline
\end{tabular}

The data presented in Table 2 allow to conclude that the raw material of thyme of the Fantasia variety in all the studied indicators, with the exception of the indicator characterizing the content of extractive substances (extracted with $70 \%$ ethanol), meets the requirements of the pharmacopoeia article FS 2.5.0097.18 of SF RF XIV edition.

Content of flavonoids and phenylpropanoids is an important indicator. It is known that luteolin in its individual state, as well as it exhibits anti-allergic and antiinflammatory properties in combination with concomitant flavonoid [17].

\section{Conclusions}

1. The common thyme variety Fantasiya is a valuable source of essential oil. The yield of essential oil in the cultivation of this variety is $40 \mathrm{~kg}$ per hectare, with a high content of the main components - thymol and carvacrol.

2. Some indicators of the quality of $T$. vulgaris cv. 'Fantasiya' raw materials are determined.

3. Raw materials of thyme of the Fantasiya variety contains a significant amount of flavonoids and can be used as a valuable pharmaceutical substance to create antiinflammatory drugs. 


\section{References}

1. Yu.V. Plugatar, O.M. Shevchuk, Bulletin of the State Nikitsky Botanical Garden, 130 (2019)

2. N.V. Marko, V.D. Rabotyagov, S.P. Korsakova, O.M. Shevchuk, S.A. Feskov, T.I. Orel, N.N. Bakova, Tavrichesky Bulletin of Agrarian Science, 3, 17 (2017)

3. O.I. Popova, D.A. Konovalov, I.V. Popov, Pharmacy, 7, 3 (2013)

4. B. Salehi, B. Krochmal-Marczak, D. Skiba, J.K. Patra, S.K. Das, G. Das, et al, Phytotherapy Research, 34(2), 315 (2020)

5. B. Salehi, D.A. Konovalov, P. Fru, P. Kapewangolo, G. Peron, M.S. Ksenija, et al, Phytotherapy Research, 34(9), 2140 (2020)

6. L.A. Fukleva, L.A. Puchkan, Scientific Bulletin of the BelSU. Series: Medicine. Pharmacy, 18(161) (2013)

7. S. Hosseinzadeh, A. Jafarikukhdan, A. Hosseini, R. Armand, International Journal of Clinical Medicine, 6 (09), 635 (2015)

8. E.M. Dauqan, A. Abdullah, Journal of Applied Biology \& Biotechnology, 5(2), 17 (2017)

9. G. Nieto, Plants. 9(8), 961 (2020)

10. B. Imelouane, H. Amhamdi, J.P. Wathelet, M. Ankit, K. Khedid, A. El Bachiri, Int. J. Agric. Biol., 11(2), 205 (2009) https://www.researchgate.net

11. M. Nikolić, J. Glamočlija, I.C. Ferreira, R.C. Calhelha, Â. Fernandes, T. Marković, ... \& M. Soković, Industrial Crops and Products, 52, 183 (2014)

12. S. Hosseinzadeh, A.J. Kukhdan, A. Hosseini, \& R. Armand, Global J Pharmacol, 9, 260 (2015)

13. State Pharmacopoeia of the RF XIV (2018) http://femb.ru

14. State Pharmacopoeia of the RF XIII (2015) http://pharmacopoeia.ru

15. V.D. Rabotyagov, L.A. Khlypenko, N.N. Bakova, V.I. Mashanov, Annotated catalog of species and varieties of essential oil, aromatic and food plants in the collection of the Nikitsky Botanical Garden, 48 (2007)

16. European Pharmacopoeia 8.0. Thyme oil, Thymol type, 1, 1405 (2014) http://mail.asmlocator.ru

17. State Pharmacopoeia of the Republic of Belarus. Thyme herb, 2, 426 (2007) https://farmstudent.ru

18. N.V. Popova, N.F. Maslova, S.I. Dikhtyarev, V.I. Litvinenko. Phytotherapy. Chasopis., 3, 43 (2010) 